\title{
Genetic differentiation among northern and southern populations of the moor frog Rana arvalis Nilsson in central Europe
}

\author{
JAN RAFIŃSKI* \& WIESŁAW BABIK \\ Department of Comparative Anatomy, Zoological Institute, Jagiellonian University, \\ Ingardena 6, 30-060 Kraków, Poland
}

\begin{abstract}
Starch gel electrophoresis and morphometric characters were used to assess the geographical variation between 14 populations of the moor frog, Rana arvalis, from northern and southern areas in Central Europe. Six of the 13 screened allozyme loci were polymorphic ( $95 \%$ criterion). No fixed differences in allele composition between the two regions were found. Some of the alleles were region specific. Genetic variability as measured by expected heterozygosity $\left(\bar{H}_{\mathrm{e}}\right)$ and number of alleles per locus was significantly lower in the southern samples than in northern ones $\left(\bar{H}_{\mathrm{e}}=0.104\right.$ and $\bar{H}_{\mathrm{e}}=0.156$, alleles/locus $=1.6$ and 1.8 respectively). This is interpreted as a consequence of the different past history of these two groups during the Pleistocene. Population subdivision, as measured by $F_{\mathrm{ST}}$, was substantial ( 0.124 and 0.078 for the southern and northern group, respectively); $59.9 \%$ of the between-locality variation is attributed to this division into two geographical groups. Isolation-bydistance was detected by significant negative correlation between the estimate of gene flow $(\log \hat{M})$ and $\log$ (geographical distance) only for the southern population groups. This indicates that the northern populations have recently recolonized their contemporary distribution area. The mean genetic distance between the northern and southern group of populations was $D_{\mathrm{N}}=0.062$. Despite the relatively low genetic distance between them, the two population groups form two distinct clusters in the maximum likelihood (ML) tree. Discriminant analysis on 11 size adjusted body measurements showed considerable overlap between populations from different geographical areas. An isolated Romanian Reci population which genetically belongs to the southern group of populations was morphologically situated in an intermediate position between northern and other southern populations.
\end{abstract}

Keywords: allozymes, amphibians, biogeography, morphometrics, population genetics, Rana arvalis.

\section{Introduction}

A dramatic decline of many amphibian species has been observed recently worldwide (Blaustein \& Wake, 1990; Wake, 1991). Nevertheless, paradoxically, the taxonomical diversity of amphibians is poorly known even in such a relatively well studied area as Europe. Recent allozymic and DNA studies have revealed the existence of several cryptic species of both anurans and urodelans in Europe (e.g. Arntzen \& García París, 1995; Nascetti et al., 1996). The assessment of biodiversity is a basic prerequisite for conservation (Galbraith, 1997). The optimal conservation strategy would be to treat as distinct conservation units genetically different groups irrespective of their taxonomic status.

*Correspondence. E-mail: rafin@zuk.iz.uj.edu.pl
The moor frog, Rana arvalis Nilsson 1842 , is widely distributed across Eurasia. Its range can be divided into two allopatric areas, a northern area which extends from eastern France to central Siberia and from the Black Sea to northern Scandinavia, and a much smaller southern one in the lowlands of the Pannonian Basin. These two areas are separated by a distributional gap in the Carpathians and in a relatively narrow strip $(60 \mathrm{~km}$ wide) in north-western Austria (Tiedeman, 1979). Populations from Central Europe inhabiting the lowlands of the middle Danube drainage area were assigned to the subspecies $R$. arvalis wolterstorffi (Fejérváry, 1919) on the basis of body proportions. Populations from the northen area of the distribution of the species are classified as a nominal form, although a few specimens with body proportions close to $R$. a. wolterstorffi have been reported from southern Poland (Ishchenko, 1997). 
On the other hand, a small group of isolated populations from Romania, which is very close to the $R$. a. wolterstorff distribution, have been described as the nominal form (Stugren, 1966).

The aim of our study was to assess the genetic differentiation between samples from the lowlands north of the Carpathians and those from the Pannonian Basin, including the isolated Romanian sample. We surveyed allozymic variation to measure the extent of genetic divergence among these three allopatric groups of populations. Additionally we looked for patterns of genetic variation within and between populations to gain insight into the past history of the moor frog populations. Since the subspecific status of European populations of Rana arvalis was based on differences in body proportions, we also studied the morphometric differentiation of the same samples which were used for electrophoretic analysis to see if morphological variation is paralleled by genetic divergence. A more detailed report on the morphological differentiation will be given elsewhere.

\section{Methods}

Samples of $R$. arvalis were taken from nine localities in Poland, four in Hungary and one in Romania (Fig. 1). Fifteen to 50 individuals per population were collected (overall 337) (Table 3). Frogs were anaesthetized with
MSS 222, measured and then stored at $-70^{\circ} \mathrm{C}$ until electrophoresis.

\section{Genetic differentiation}

We scored electrophoretic variation in 11 enzyme systems coded by 13 presumptive allozyme loci, using standard horizontal starch gel electrophoresis (Murphy et al., 1996). All enzymes were scored from muscle homogenates. The loci surveyed and buffer systems used are listed in Table 1. Staining procedures were adapted from Murphy et al. (1996) with slight modifications. Alleles from different populations were calibrated relative to each other by running samples from different populations on the same gel. Allele frequencies and the matrix of genetic distances are available from the authors upon request.

Deviations from genotype frequencies expected under the Hardy-Weinberg equilibrium were tested using the GENEPOP ver. 3.1 program (Raymond \& Rousset, 1995). Tests were combined across loci and across localities using Fisher's method. Because multiple tests were performed, we adjusted the significance level using the sequential Bonferroni procedure (Lessios, 1992). Gametic disequilibrium between loci was tested using GENEPOP. Allele frequencies and measures of variability [per cent of polymorphic loci ( $95 \%$ criterion), unbiased mean expected heterozygosity (Nei, 1978) and number
Fig. 1 Distribution of sampling localities for $R$. arvalis in Central Europe (combined from Tiedeman, 1979 and Ishchenko, 1997). Acronyms correspond to localities: BIA, Białowieża; CHE, Chełm; DEB, Debrecen; DWI, Dwikozy; FEH, Fehértó; JEZ, Jeziorzany; KOL, Kotobrzeg; REC, Reci; ROG, Rogaczewo; TIS, Tiszaalpár; TOK, Tokaj; WAL, Walawa; WYS, Wysoka Kamieńska; ZWO, Zwoleń. Distribution of $R$. arvalis is hatched. A contour line $500 \mathrm{~m}$ a.s.l. is shown.

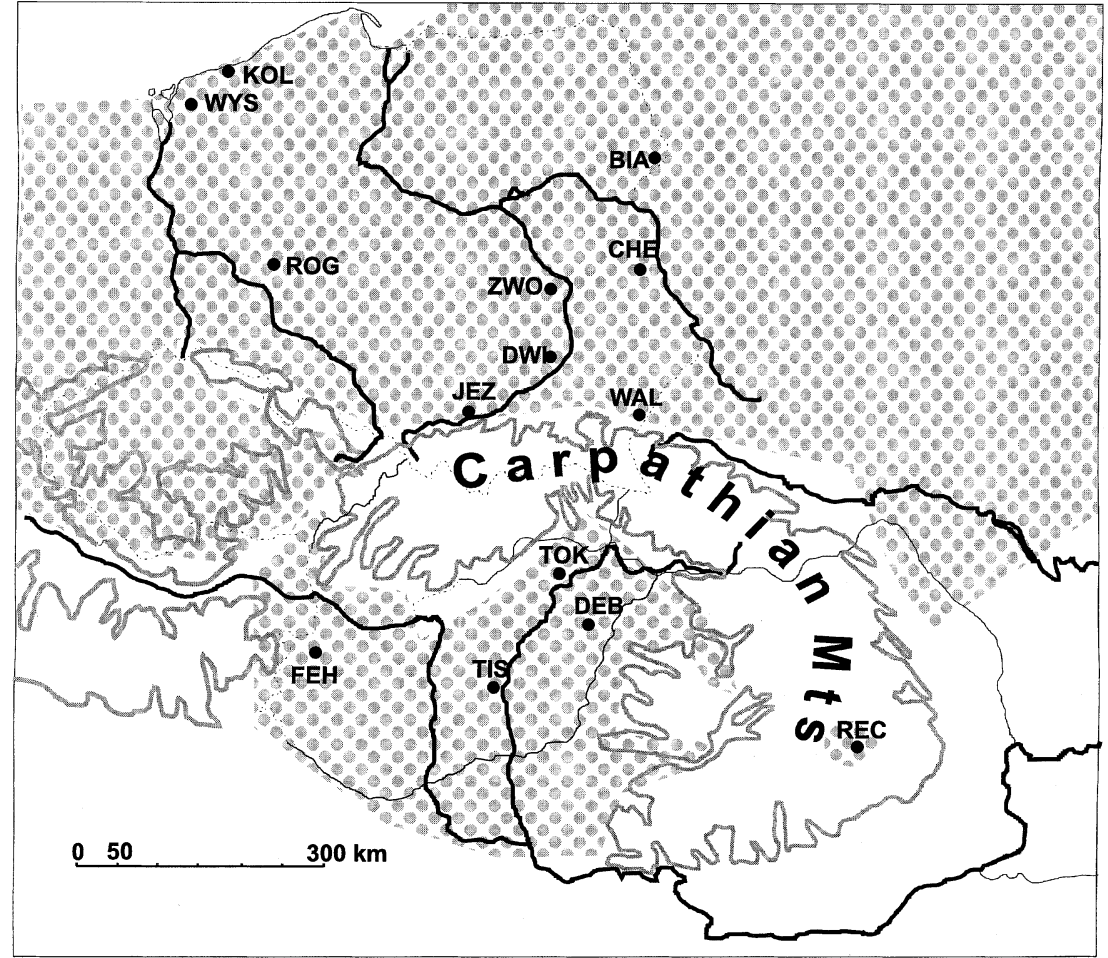


Table 1 Enzyme systems used in electrophoretic study of R. arvalis

\begin{tabular}{|c|c|c|c|}
\hline Enzyme & E.C. No. & Locus & Buffer \\
\hline Aspartate & & & \\
\hline $\begin{array}{l}\text { Aminotransferase } \\
\text { Glucose-6-phosphate }\end{array}$ & 2.6.1.1 & Aat-1 & $\mathrm{LiOH}$ \\
\hline $\begin{array}{l}\text { Isomerase } \\
\text { L-Lactate }\end{array}$ & 5.3.1.9 & Gpi & $\mathrm{TC}$ \\
\hline $\begin{array}{l}\text { Dehydrogenase } \\
\text { Malate }\end{array}$ & 1.1 .1 .27 & $L d h-1, L d h-2$ & $\mathrm{TC}$ \\
\hline $\begin{array}{l}\text { Dehydrogenase } \\
\text { Mannose-6-phosphate }\end{array}$ & 1.1.1.37 & $M d h-1, M d h-2$ & $\mathrm{TC}$ \\
\hline Isomerase & 5.3 .1 .8 & $M p i$ & $\mathrm{LiOH}$ \\
\hline Creatine kinase & 2.7 .3 .2 & $C k$ & TC \\
\hline $\begin{array}{l}\text { Adenylate kinase } \\
\text { Isocitrate }\end{array}$ & 2.7.4.3 & $A k$ & $\mathrm{TC}$ \\
\hline $\begin{array}{l}\text { Dehydrogenase } \\
\text { Phosphogluconate }\end{array}$ & 1.1 .1 .42 & $I d h-2$ & $\mathrm{TC}$ \\
\hline Dehydrogenase & 1.1 .1 .44 & $P g d h$ & $\mathrm{TC}$ \\
\hline Peptidase (Leu-Tyr) & 3.4.-.- & Рep & $\mathrm{LiOH}$ \\
\hline Phosphoglucomutase & 5.4 .2 .2 & Pgm & TC \\
\hline
\end{tabular}

LiOH, lithium-borate buffer $\mathrm{pH} 8.1 / 8.4$; TC, tris-citric acid buffer pH 7.0.

of alleles per locus] were computed using BIOsYs-1 (Swofford \& Selander, 1989). Tests of differentiation of allele frequencies between localities were performed using the permutation method as implemented in GENEPOP with the $P$ level adjusted using the sequential Bonferroni procedure.

Genetic differentiation among the populations was measured using Nei's (1978) unbiased genetic distance. We chose Nei's distance since it is the most widely used and allows comparisons with other data. To estimate the time of divergence between the northern and southern R. arvalis populations we also computed Hillis' modified Nei genetic distance (Hillis, 1984). This distance was used by Beerli et al. (1996) to calibrate the molecular clock for the European green frogs and we employed this calibration for our data.

To summarize the genetic relatedness between populations, maximum likelihood (ML) analysis based on the raw allele frequency matrix was performed. We constructed the ML tree with the CONTML program in PHYLIP ver. 3.5 (Felsenstein, 1993). To assess the support for our ML tree we performed the bootstrap resampling (100 pseudoreplications), using SEQBOOT and CONSENSE programs in PHYLIP.

Genetic divergence among populations was expressed by Wright's $F_{\mathrm{ST}}$-statistic (Wright, 1978), which was then used to infer the level of gene flow between the populations studied. Weir and Cockerham's (1984) estimates of Wright's $F_{\mathrm{ST}}$ were computed for variable loci with FSTAT ver. 1.2 (Goudet, 1995). Means and standard deviations of $F_{\mathrm{ST}}$ estimates were obtained by jackknifing over loci, whereas $95 \%$ confidence intervals were obtained by bootstrapping over loci (15000 replications). The permutation tests as implemented in FSTAT (5000 permutations) were performed to test if $F_{\mathrm{ST}}$ estimates were significantly different from 0 . Hierarchical gene diversity analysis (Wright, 1978) was performed using BIosys-1. Localities were grouped into two geographical regions: all samples from Polish localities were grouped to form the "northern region", and the remaining, Hungarian and Romanian localities were grouped to form the "southern region".

The influence of gene flow on the genetic divergence of populations was inferred from values of pairwise $F_{\mathrm{ST}}$ from the formula of Wright (1978): $\quad F_{\mathrm{ST}}=$ $1 /\left(1+4 N_{\mathrm{e}} m\right), N_{\mathrm{e}} m$ being the measure of gene flow between populations (Slatkin \& Barton, 1989). As an estimator of $N_{\mathrm{e}} m$ we computed pairwise values of $\hat{M}$ according to Slatkin (1993). We have not treated the $\hat{M}$ value as an indirect measure of migration and gene flow, instead we looked for the association between geographical distance and $\hat{M}$ values. Such association indicates that the pattern of genetic divergence of populations as measured by $\hat{M}$ has been significantly influenced by genetic drift and gene flow. The negative correlation between $\log$ (geographical distance) and $\log (\hat{M})$ fits the expectations to the model of isolationby-distance (Slatkin, 1991). In a one-dimensional stepping-stone model the expected slope of a regression of $\log (\hat{M})$ vs. $\log$ (geographical distance) is -1.0 , and under the two-dimensional stepping-stone model the expected slope is approximately -0.5 (Slatkin, 1991). Geographical distances between localities were taken from maps as shortest aerial kilometers. The significance of the relationship between $\log (\hat{M})$ and $\log ($ geographical distance) was assessed by Mantel's test using NTSYS-PC (Rohlf, 1992). One-tailed $P$ values were reported.

\section{Morphological differentiation}

Twelve external measurements (six from the head, snout-vent length (SVL) and five from the hindlimb) were taken (Table 2) from 319 frogs (15 to 30 from each population), most of which were subsequently used for electrophoresis. All the measurements were taken by one of us (J.R.) on frogs anaesthetized with MS 222 with precision vernier callipers to the nearest $0.1 \mathrm{~mm}$. Raw morphometric data were log-transformed and all measurements except seven were size-adjusted by the allometric method (Thorpe, 1976); the (SVL) was taken as a general size measurement. As the common slope we used pooled within-locality slope (Thorpe, 1976). Adjusted values were subjected to discriminant analysis where 
Table 2 Morphometric measurements

\begin{tabular}{|c|c|c|c|}
\hline No. & Measure & Abbreviation & Description \\
\hline 1. & Internarial distance & IND & Measured between mean edges of nares \\
\hline 2. & Anterior interorbital distance & AID & Distance between anterior edges of eyes \\
\hline 3. & Interorbital distance & $\mathrm{IO}$ & Shortest distance between eye sockets \\
\hline 4. & Posterior inteorbital distance & PID & Distance between posterior edges of eyes \\
\hline 5. & Eye-naris distance & END & $\begin{array}{l}\text { Distance between anterior edge of eye and posterior } \\
\text { edge of naris }\end{array}$ \\
\hline 6. & Tympanum diameter & TD & Maximum distance between rims of tympanum \\
\hline 7. & Snout-vent length & SVL & From tip of snout to posterior margin of vent \\
\hline 8. & Femur length & FL & Anus to knee \\
\hline 9. & Tibia length & TL & Knee to heel \\
\hline 10. & Foot length & $\mathrm{F}$ & Tip of longest toe to back of heel \\
\hline 11. & First toe length & $\mathrm{T} 1$ & From tip to articulation with foot \\
\hline 12. & Internal metatarsal tubercle length & IMT & Maximum length \\
\hline
\end{tabular}

localities formed a priori groups, using STATISTICA rel. 5.1 (StatSoft, 1997).

\section{Results}

\section{Genetic variation}

None of the loci showed departures from the HardyWeinberg equilibrium and genotypes at all the loci were independent; none of the pairwise chi-squared tests (Fisher's method, as implemented in GENEPOP) were significant. The percentage of polymorphic loci $(95 \%$ criterion) ranged from 23.1 (REC) to 53.8 (TOK) (Table 3). The mean value for northern populations was 42.77 and for southern populations was 44.25.
Differences between the regions were not statistically significant (two tailed Mann-Whitney U test, $P=0.72$ ). For two other measures of genetic variation, mean heterozygosity $\left(\bar{H}_{\mathrm{e}}\right)$ and the number of alleles per locus, northern populations showed significantly higher values than southern ones $\left(\bar{H}_{\mathrm{e}}=0.156\right.$ vs. 0.104 and no. alleles $=1.78$ vs. 1.62 , two tailed Mann-Whitney $\mathrm{U}$ test $P=0.003$ and $P=0.004$, respectively). A sample from the marginal population at Reci (REC) showed much lower values for all three measures of genetic variation (Table 3).

The differences in mean expected heterozygosity and mean number of alleles per locus between geographical regions are due mostly to two loci: Aat-l and Pgm. The total number of $P g m$ alleles in northern samples was

Table 3 Expected unbiased heterozygosities (Nei, 1978), percentage of polymorphic loci (95\% criterion) and number of alleles per locus in investigated populations

\begin{tabular}{lllcc}
\hline Population & $n$ & \multicolumn{1}{c}{$\bar{H}_{\mathrm{e}}$} & \% polymorphic loci & No. alleles/locus \\
\hline ZWO & 27 & 0.132 & 46.2 & 1.9 \\
WYS & 15 & 0.164 & 46.2 & 1.8 \\
ROG & 21 & 0.165 & 53.8 & 1.8 \\
BIA & 19 & 0.155 & 38.5 & 1.8 \\
JEZ & 50 & 0.156 & 38.5 & 1.8 \\
WAL & 19 & 0.141 & 38.5 & 1.7 \\
CHE & 20 & 0.169 & 38.5 & 1.7 \\
DWI & 22 & 0.158 & 38.5 & 1.8 \\
KOL & 16 & 0.167 & 46.2 & $1.78(0.06)$ \\
Northern mean (SD) & 23.2 & $0.1563(0.0124)$ & $42.77(5.57)$ & 1.7 \\
FEH & 23 & 0.103 & 46.2 & 1.7 \\
TIS & 26 & 0.096 & 38.5 & 1.6 \\
TOK & 24 & 0.125 & 53.8 & 1.5 \\
DEB & 29 & 0.091 & 38.5 & 1.2 \\
REC & 26 & 0.075 & 23.1 & $1.62(0.10)$ \\
Southern mean (SD) & 25.6 & $0.1038(0.0150)$ & $44.25(7.33)$ & \\
\hline
\end{tabular}

$n$, number of individuals studied.

(C) The Genetical Society of Great Britain, Heredity, 84, 610-618. 
seven. Moreover all seven of these alleles segregated in some of the northern populations, whereas in southern populations five alleles were detected, but at most only three were present within a single population. In all southern samples always one allele $(\operatorname{Pgm} c)$ occurred in high frequencies.

We have not found any locus at which different alleles were fixed in the northern and southern population groups. However, some of the alleles were found exclusively either in northern or southern populations; $I d h-2$ a, Pgm a and Pgm $d$ were detected only in the northern group, whereas $P g d h a, P g d h c$ and $M p i c$ were only found in the southern group. In the northern populations we found only one rare allele $(I d h-2 a)$, with a frequency lower than 0.05 , whereas in the southern group we found four such alleles (Aat-1 c, Gpi c, Pgdh a and $P g d h \quad c)$. Highly significant differences in allele frequencies among all the populations were found at six loci: Aat-1, Gpi, Ldh-2, Mdh-1, Mpi and Pgm, (in all comparisons $P<0.001)$. In the northern populations significant differences were found at Aat-1 $(P<0.001)$, Pgm $(P<0.001), \quad$ Gpi $(P<0.05)$ and $M d h-1$ $(P<0.05)$; in southern populations at Gpi, Ldh-2, $M d h-1, M p i$ and $P g m$ (all $P<0.001$ ). All $P$ values were adjusted using the sequential Bonferroni method.

\section{Genetic divergence}

The values of $D_{\mathrm{N}}$ computed for our samples were generally low and ranged from close to zero (ROGWYS) to 0.109 (FEH-BIA). The mean distance value among the northern populations was close to that for the southern populations; these values reached 0.013 and 0.014 , respectively, whereas the mean distance between the northern and southern populations was much higher $\left(D_{\mathrm{N}}=0.062\right)$.

The southern and northern populations form two distinct groups in the maximum likelihood tree $(100 \%$ support for grouping all the southern populations together) (Fig. 2).

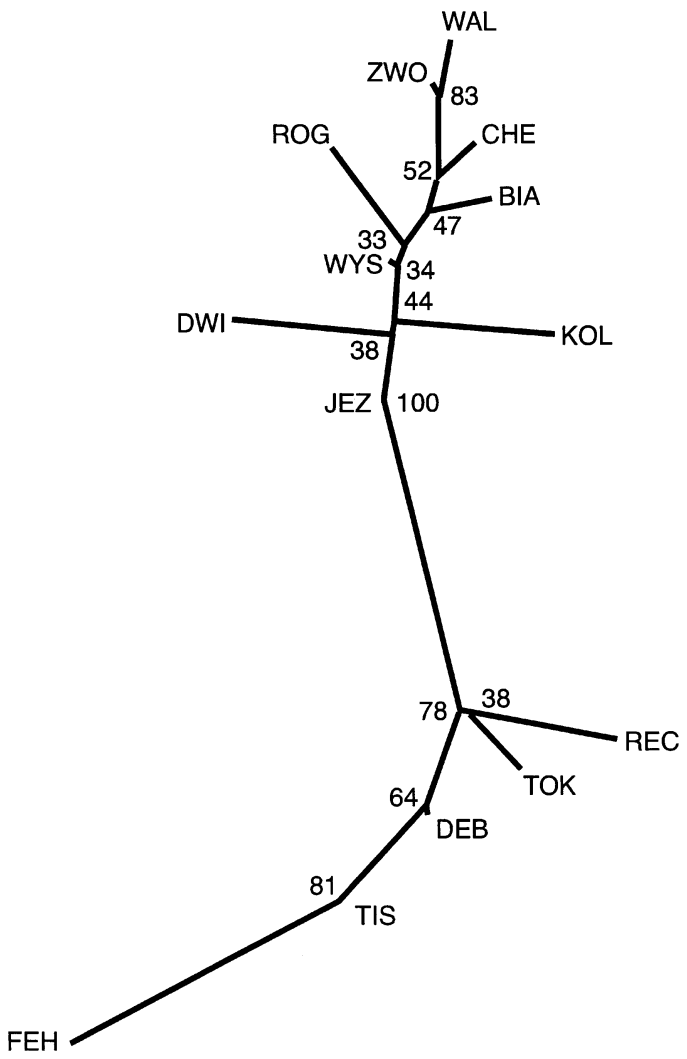

Fig. 2 Maximum likelihood tree obtained for the $R$. arvalis populations. Numbers give the bootstrap support for a particular node.

\section{Population structure and gene flow}

The analysis of Wright's $F_{\mathrm{ST}}$ showed substantial genetic differentiation among populations. $F_{\mathrm{ST}}$ values estimated by $\theta$ for all samples, and separately for populations from the northern and the southern group were equal to $0.202,0.078$ and 0.124 , respectively (Table 4). A twolevel hierarchical analysis of $F_{\mathrm{ST}}$ values performed using Wright's approach (Wright, 1978) demonstrated that $40.1 \%$ of among-localities variance was the result of

Table 4 Weir and Cockerham's (1984) $\theta$ estimators of $F_{\mathrm{ST}}$ for all populations and for two geographical regions separately

\begin{tabular}{|c|c|c|c|c|c|c|c|c|c|c|c|c|}
\hline & Aat-1 & $G p i$ & $L d h-2$ & $M d h-1$ & $M p i$ & $P g d h$ & Pgm & $\begin{array}{c}\text { Jacknifed } \\
\text { average }\end{array}$ & SD & $\begin{array}{l}\text { Lower } \\
95 \% \text { CI }\end{array}$ & $\begin{array}{c}\text { Upper } \\
95 \% \text { CI }\end{array}$ & $P$ \\
\hline $\begin{array}{l}\text { All } \\
\theta\end{array}$ & 0.319 & 0.065 & 0.044 & 0.070 & 0.130 & 0.014 & 0.233 & 0.202 & 0.053 & 0.066 & 0.267 & $<0.0002$ \\
\hline $\begin{array}{l}\text { Northern } \\
\theta\end{array}$ & 0.167 & 0.040 & 0.016 & 0.041 & -0.008 & $*$ & 0.055 & 0.078 & 0.037 & 0.016 & 0.134 & $<0.0002$ \\
\hline $\begin{array}{l}\text { Southern } \\
\theta\end{array}$ & 0.003 & 0.098 & 0.109 & 0.139 & 0.165 & 0.008 & 0.103 & 0.124 & 0.023 & 0.059 & 0.148 & $<0.0002$ \\
\hline
\end{tabular}

$P$, probability that $\theta$ is not $>0$.

* Only one allele detected in northern group. 
variation within the region, whilst the remaining 59.9\% was due to differences between the regions (Table 5).

Ordinal least squares regression of $\log (\hat{M})$ on $\log$ (geographical distance) for all localities gave a slope equal to -0.894 , and this correlation was statistically significant ( $r=-0.438, P=0.0014$, Mantel test). When the same analysis was performed separately for the northern and the southern group, only in the latter group did it show significant negative correlation $(r=-0.972, P=0.0419$, Mantel test $)$ with a regression slope $=-1.175$. No significant correlation was detected for the northern populations $(r=0.204, P=0.8554$, Mantel test), regression slope $=0.063$ (Fig. 3). To assess the influence of any single locus on the geographical pattern of genetic variation among southern popula-

Table 5 Hierarchical gene diversity analysis (Wright, 1978)

\begin{tabular}{llcc}
\hline & $\begin{array}{c}\text { Total } \\
\text { variance }\end{array}$ & $\begin{array}{c}\text { Relative } \\
(\%)\end{array}$ & $\begin{array}{c}\text { Relative } \\
(\%)\end{array}$ \\
\hline Total & 2.143 & 100 & \\
Within localities & 1.757 & 82.0 & \\
Between localities & 0.386 & 18.0 & 100 \\
Within regions & 0.154 & & 40.1 \\
Between regions & 0.231 & & 59.9 \\
\hline
\end{tabular}
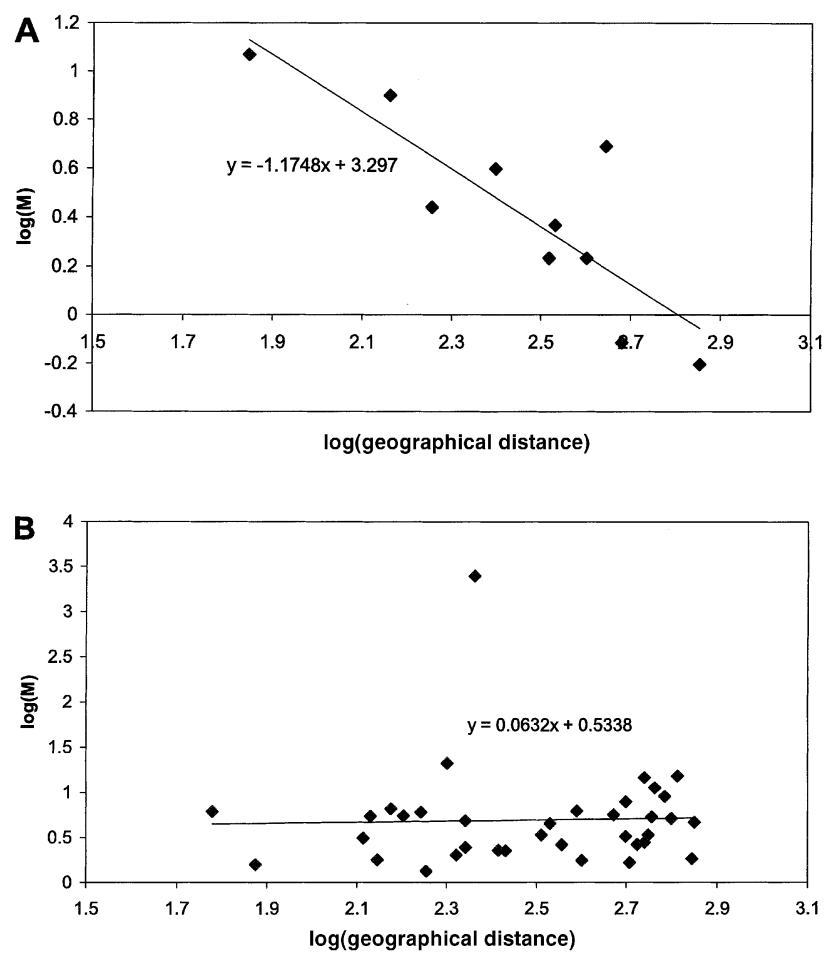

Fig. 3 Log-log plot of Slatkin's (1993) $\hat{M}$ vs. map distance between populations of $R$. arvalis. A, populations from the southern region; $\mathrm{B}$, populations from the northern region. tions, we excluded loci one at a time (jackknifed over loci) and recalculated the parameters of the regression lines (Table 6). This analysis demonstrated that all loci produced similar values of $\hat{M}$.

\section{Morphological differentiation}

The first and second canonical root of discriminant analysis accounted for over $72 \%$ of the total variance in morphological characters. A plot of canonical scores of specimens showed a substantial separation of individuals from the southern and northern populations, with individuals from Reci (REC) being morphologically intermediate (Fig. 4). Because we used localities as a grouping variable, separation of geographical regions was not the result of an a priori division into three geographical groups. Although the mean probability of assigning an individual to the correct locality was only

Table 6 Slopes and intercepts of regression lines of $\log (\hat{M})$ vs. $\log$ (geographical distance) for southern populations obtained after dropping given locus from analysis

\begin{tabular}{lcc}
\hline & Slope & Intercept \\
\hline Aat-1 & -1.157 & 3.205 \\
Gpi & -1.457 & 4.033 \\
Ldh-2 & -1.208 & 3.385 \\
Mdh-1 & -0.978 & 2.805 \\
Mpi & -1.047 & 3.089 \\
Pgdh & -1.171 & 3.277 \\
Pgm & -1.371 & 3.762 \\
Mean & -1.1984 & 3.3650 \\
SD & 0.1686 & 0.4139 \\
\hline
\end{tabular}

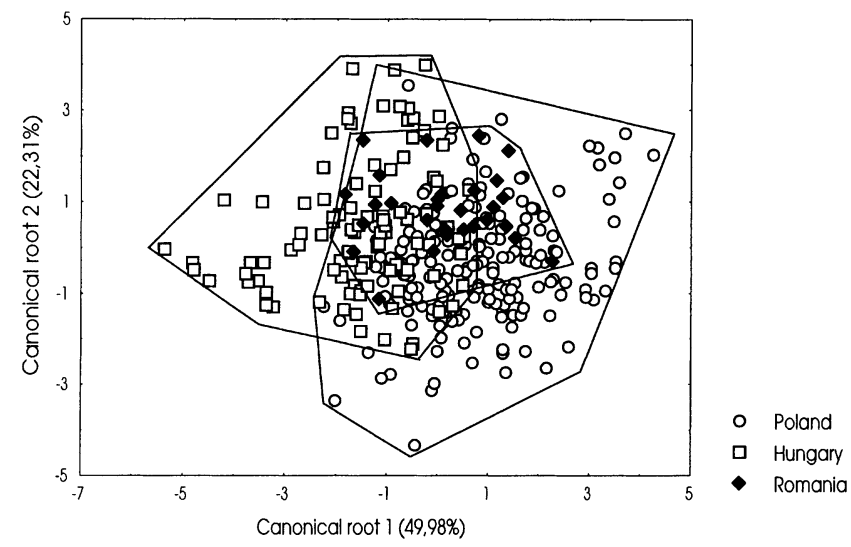

Fig. 4 Scatterplot of discriminant scores on canonical root 1 and 2. Localities were used as a grouping variable. Analysis was performed on size-adjusted measurements (see text). In parentheses per cent of total variance explained by the given canonical root. 
$53 \%, 85 \%$ of cases were correctly classified to a geographical region.

\section{Discussion}

Our electrophoretic study revealed that genetic diversity within $R$. arvalis populations as measured by $\bar{H}_{\mathrm{e}}$ and the mean number of alleles per locus, was higher in the northern region than in the southern group of populations. This result was unexpected since all northern populations came from an area which was glaciated during the Pleistocene (Turner, 1996). A relatively low level of genetic variation has been reported for both plant and animal populations from glaciated areas in Europe and North America (Highton \& Webster, 1976; Green et al., 1996; Merilä et al., 1996). We expected to find lower genetic diversity also in northern $R$. arvalis samples, since northern populations of the species have recently colonized their present area of distribution. Fossil remains of $R$. arvalis from northern localities (Mecklemburg, northern Germany) are known only from the time after the last glaciation (Böhme, 1982). A relatively high variation in our northern group of $R$. arvalis excludes the possibility of drastic population size changes during postglacial colonization of the plains north of the Carpathians. The moor frog is now distributed far to the east (Ishchenko, 1997). The southern part of this eastern distribution probably was a Pleistocene refugium from where the moor frog reinvaded the lowlands of Europe north of the Carpathians.

To our surprise, southern populations of $R$. arvalis exhibited significantly reduced genetic diversity as measured by mean heterozygosity and number of alleles per locus $\left(\bar{H}_{\mathrm{e}}=0.156\right.$ vs. 0.104 and no. alleles $=1.78$ vs. 1.62 in the northern and southern regions, respectively). Paleontological data indicate that the moor frog inhabited the Pannonian Basin throughout the Pleistocene (Venczel, 1997; pers. comm.). Genetic variation of southern populations was most probably reduced by single or repeated bottlenecks caused by multiple climatic fluctuations during the Pleistocene. A higher number of rare alleles found in southern populations than northern ones could also be explained by the action of genetic drift (Chakraborty et al., 1980). Our Reci sample from central Romania has the lowest genetic variation (see Table 3). A small group of populations from Reci is separated by a distributional gap from the rest of the southern populations and is most likely a relic of a wider distribution of $R$. arvalis south of the Carpathians in the past (Fig. 1). The significant reduction of genetic variability in the Reci population is probably a result of population shrinkage caused by the climatic changes.
We detected contrasting patterns of the relationship between $\log (\hat{M})$ and $\log$ (geographical distance) in the northern and southern population group of $R$. arvalis. A significant negative correlation between $\log (\hat{M})$ and $\log$ (geographical distance) with the regression slope close to -1.0 in the southern group indicates isolationby-distance, consistent with the one-dimensional stepping-stone model (Slatkin, 1993) (Fig. 3). Populations of the moor frog are distributed primarily along river valleys (Ishchenko, 1997) and it is realistic to assume that the pattern of migration in this species is closer to a theoretical one-dimensional stepping-stone model than to the two-dimensional stepping-stone or the island model. The lack of isolation-by-distance in northern populations stems primarily from high $\hat{M}$ values between distant pairs of populations (Fig. 3). Such a pattern would be expected following the recent range expansion (Slatkin, 1993), which would result in a transient but high level of inferred gene flow between distant populations. These contrasting patterns are concordant with the hypothesized past history of $R$. arvalis populations.

The use of $F_{\mathrm{ST}}$ as an indirect measure of gene flow and migration has been questioned recently (Whitlock \& McCauley, 1999). Genetic divergence of populations as measured by $F_{\mathrm{ST}}$ may be caused by several other factors besides gene flow, and derivation of gene flow from measures such as $F_{\mathrm{ST}}$ or $\hat{M}$ may be unwarranted, because the model assumptions are simplified and unrealistic. Jackknifing the $\hat{M}$ values over loci showed that individual polymorphic loci contribute similarly to estimates of $\hat{M}$ (Table 6), and since no tight linkage between loci was discovered, the distorting effect of natural selection is highly unlikely for our data. The strong association between $\hat{M}$ values and geographical distances which we discovered in the southern group of populations is therefore most parsimoniously explained by a simple model of isolation-by-distance (Slatkin, 1993). Populations from the southern region have had much more time to reach an equilibrium between gene flow and genetic drift than the populations which recently colonized the northern region.

Populations of $R$. arvalis from the areas north and south of the Carpathians form two genetically well separated groups, although their genetic divergence is relatively low (Fig. 2). There are no loci fixed for different alleles between these groups and these two groups differ mainly in allele frequencies. The genetic distance between the northern and southern populations of $R$. arvalis is much lower than the mean distance reported for interspecific differences in amphibians (Thorpe, 1982). Despite the low genetic distance values between the southern and northern groups, these two groups are nevertheless unequivocally genetically distinct (Fig. 2). 
Low values of genetic distances between the two groups (mean $D_{\mathrm{N}}=0.062$ ) indicates that they separated relatively recently. Green \& Borkin (1993) reported a very similar value of $D_{\mathrm{N}}=0.056$ in an electrophoretic study of the moor frog in which one sample came from the range of our southern group and two samples from a distant northern area. These two independent estimates of $D_{\mathrm{N}}$ values are very close, despite the fact that Green $\&$ Borkin sampled a significantly larger number of loci (25); this adds confidence to our estimates of genetic divergence. Beerli et al. (1996), calibrated the rate of genetic divergence of $0.10 D_{\mathrm{N}}^{*} / \mathrm{Myr}$ for European green frogs using geological dates. These authors used a modified Nei's genetic distance (Hillis, 1984). When we recalculated the genetic distances of our data, the value we obtained was $D_{\mathrm{N}}^{*}=0.103$, giving the isolation time of 0.7-1.3 Myr. There is evidence (Webb \& Bartlein, 1992) that 500000 to 850000 years before present the glaciations were especially severe, and this probably caused the separation of the moor frog gene pool into the northern and southern groups.

The clear genetic divergence of the moor frog in Central Europe is not accompanied by similar morphological differentiation (Fig. 4). All southern populations except Reci (Romania) were classified on the basis of body proportions as a distinct subspecies $R$. arvalis wolterstorffi, whereas an isolated group of $R$. arvalis populations from central Romania was classified as a nominal form (Fejérváry, 1919; Stugren, 1966). Our allozymic study showed that the sample from Reci is genetically much closer to the other southern (Hungarian) populations than to northern populations (Fig. 2). Analysis of body proportions showed that there is considerable overlap between groups and that the population from Reci occupies an intermediate position between the northern group of populations and the remaining southern populations (Fig. 4). We see no justification in distinguishing subspecific taxa in the European population of the moor frog based on morphological differentiation for two reasons. First, large morphological variability does not allow a clear separation of populations formerly described as belonging to $R$. arvalis wolterstorffi from the nominal form, and second the concordance between the genetic and morphological differentiation is weak. However the southern populations of $R$. arvalis are clearly distinct genetically from the northern populations and therefore their treatment as a separate conservation unit is recommended.

\section{Acknowledgements}

We wish to thank Dr J. M. Szymura for many helpful comments during manuscript preparation and
Dr R. S. Thorpe for help in morphometric analysis. We also thank the communicating editor and two anonymous referees for their comments on the manuscript. Dr Z. Korsós helped in collection of Hungarian samples. Dr D. Cogălniceanu kindly provided a sample of frogs from Romania. Dr M. Rybacki collected frogs from western Poland. This study has been supported partially by a research grant $\mathrm{DS} / 30 / \mathrm{IZ} / 99$.

\section{References}

ARNTZEN, J. W. AND GARCíA PARís, M. 1995. Morphological and allozyme studies of midwife toads (genus Alytes), including the description of two new taxa. Contr. Zool., 65, 5-34.

BEERLI, P., HOTZ, H. AND UZZELL, T. 1996. Geologically dated sea barriers calibrate a protein clock for Aegean water frogs, Evolution, 50, 1676-1687.

BlAUSTEIN, A. R. AND WAKE, D. B. 1990. Declining amphibian populations: a global phenomenon? Trends Ecol. Evol., 5, 203-204.

вÖHME, G. 1982. Zur Geschichte der Anuren-Fauna Europas. Wissenschaftl. Zeitschr. Humboldt-Univ. Berlin, Math.-Nat., 31, 147-149.

CHAKRABORTY, R., FUERST, P. A. AND NEI, M. 1980. Statistical studies on protein polymorphism in natural populations. III. Distribution of allele frequencies and the number of alleles per locus. Genetics, 94, 1039-1063.

FEJÉRVÁRY, G. J. 1919. On two south-eastern varieties of Rana arvalis Nilss. Ann. Mus. Nat. Hung., 17, 178-183.

FELSENSTEIN, J. 1993. PHYLIP (Phylogeny Inference Package) version 3.5c. Dept. Genetics, SK-50, University of Washington, Seattle, WA.

GALBRAITH, D. A. 1997. The role of molecular genetics in the conservation of amphibians. In: Green, D. M. (ed.) Amphibians in decline: Canadian studies of a global problem. Herpetological Conserv., 1, 282-290.

GOUDET, J. 1995. FSTAT v-1.2: a computer program to calculate F-statistics. J. Hered., 86, 485-486.

GREEN, D. M. AND BORKIN, L. J. 1993. Evolutionary relationships of Eastern Palearctic Brown Frogs, genus Rana: paraphyly of the 24-chromosome species group and the significance of chromosome number change. Zool. J. Linn. Soc., 109, 1-25.

GREEN, D. M., SHARbel, T. F., KEARSLEY, J. AND KAISER, H. 1996. Postglacial range fluctuation, genetic subdivision and speciation in the western North American spotted frog complex, Rana pretiosa. Evolution, 50, 374-390.

HIGHTON, R. AND WEBSTER, T. P. 1976. Geographic protein variation and divergence in populations of the salamander Plethodon cinereus. Evolution, 30, 33-45.

HILlis, D. M. 1984. Misuse and modification of Nei's genetic distance. Syst. Zool., 33, 238-240.

ISHCHENKO, v. 1997. Rana arvalis Nilsson, 1842. In: Gasc, J.-P. (ed.) Atlas of Amphibians and Reptiles in Europe, pp. 128-129. Muséum National D'Histoire Naturelle, Paris.

LESSIOS, H. A. 1992. Testing electrophoretic data for agreement with Hardy-Weinberg expectations. Marine Biol., 112, $517-523$. 
MERILÄ, J., BJÖRKLUND, M. AND BAKER, A. J. 1996. Genetic population structure and gradual northward decline of genetic variability in the greenfinch (Carduelis chloris). Evolution, 50, 2548-2557.

MURPHY, R. W., SITES, J. W., BUTH, D. G., AND HAUFLER, C. H. 1996. Proteins: isozyme electrophoresis. In: Hillis, D. M., Moritz, C. and Mable, B. K. (eds) Molecular Systematics, pp. 51-120. Sinauer Associates, Sunderland, MA.

NASCETTI., G., CIMMARUTA, R., LANZA, B. AND BULLINI, L. 1996. Molecular taxonomy of European Plethodontid Salamanders. J. Herpetol., 30, 161-183.

NEI, M. 1978. Estimation of average heterozygosity and genetic distance from a small number of individuals. Genetics, 89 , 583-590.

RAYMOND, M. AND ROUSSET, F. 1995. GENEPOP (version 1.2): a population genetics software for exact tests and ecumenicism. J. Hered., 86, 248-249.

ROHLF, F. J. 1992. NTSYS-PC, Numerical taxonomy and multivariate analysis system, version 1.80. Applied Biostatistics, Setauket, NY.

SLATKIN, M. 1991. Inbreeding coefficients and coalescence times. Genet. Res., 58, 167-175.

SLATKIN, M. 1993. Isolation by distance in equilibrium and non-equilibrium populations. Evolution, 47, 264-279.

SlATKIN, M. AND BARTON, N. H. 1989. A comparison of three indirect methods for estimating average levels of gene flow. Evolution, 43, 1349-1368.

STUGRen, B. 1966. Geographic variation and distribution of the Moor Frog, Rana arvalis Nilss. Ann. Zool. Fenn., 3, 29-39.
SWOFFORD, D. L. AND SELANDER, R. B. 1989. BIOSYS-1. A computer program for the analysis of allelic variation in population genetics and biochemical systematics. Release 1.7. Illinois Natural History Survey, Champaign, IL.

THORPE, J. P. 1982. The molecular clock hypothesis: biochemical evolution, genetic differentiation and systematics. Ann. Rev. Ecol. Syst., 13, 139-168.

THORPE, R. S. 1976. Biometric analysis of geographic variation and racial affinities. Biol. Rev., 51, 407-452.

TIEDEMAN, F. 1979. Erstnachweis von Rana a. arvalis in Österreich (Amphibia: Salientia: Ranidae). Salamandra, 15, 180-184.

TURNER, C. (ed.) 1996. The Early Middle Pleistocene in Europe. Balkema, Rotterdam.

VENCZEL, M. 1997. Amphibians and reptiles from the lower Pleistocene of Osztramos (Hungary). Nymphaea, 23-25, 77-88.

WAKE, D. B. 1991. Declining amphibian populations. Science, 253, 860.

WEBB, T. AND BARTLEIN, P. J. 1992. Global changes during last 3 million years: climatic controls and biotic responses. Ann. Rev. Ecol. Syst., 23, 141-173.

WEIR, B. S. AND COCKERHAM, C. C. 1984. Estimating F-statistics for the analysis of population structure. Evolution, 38, 1358-1370.

WHITLOCK, M. C. AND MCCAULEY, D. E. 1999. Indirect measures of gene flow and migration: $F_{\mathrm{ST}} \neq 1 /(4 \mathrm{Nm}+1)$. Heredity, 82, 117-125.

Wright, s. 1978. Evolution and the Genetics of Populations, vol. 4, Variability Within and Among Natural Populations. University of Chicago Press, Chicago, IL. 